\title{
mTOR Inhibitors and Calcineurin Inhibitors Do Not Affect Adhesion Molecule Expression of Human Macro- and Microvascular Endothelial Cells
}

\author{
Karla Lehle $^{\mathrm{a}}$ Stephan Schreml ${ }^{\mathrm{a}}$ Leoni A. Kunz-Schughart ${ }^{\mathrm{b}, \mathrm{c}}$ \\ Leopold Rupprecht $^{\mathrm{a}}$ Dietrich E. Birnbaum ${ }^{\mathrm{a}}$ Christof Schmid ${ }^{\mathrm{a}}$ \\ Jürgen G. Preuner ${ }^{a}$ \\ ${ }^{a}$ Department of Cardiothoracic Surgery and ${ }^{b}$ Institute of Pathology, University of Regensburg, Regensburg, \\ and ${ }^{\mathrm{C} O n c o R a y}$ - Center for Radiation Research in Oncology, Medical Faculty Carl Gustav Carus, TU Dresden, \\ Dresden, Germany
}

\section{Key Words \\ Adhesion molecules $\cdot$ Calcineurin inhibitors $\cdot$ mTOR \\ inhibitors · E-selectin - ICAM-1 - VCAM-1}

\begin{abstract}
We examined the effect of cyclosporin A, tacrolimus, sirolimus and everolimus on the cell growth, viability, proliferation, expression of cellular adhesion molecules (CAM) and leukocyte (PBMC) binding of human macrovascular (coronary artery, saphenous vein) and microvascular endothelial cells (EC). Tacrolimus did not affect EC integrity, growth or expression of CAM. Exclusively, EC from the coronary arteries showed a reduced cellular growth (about 30\%) under cyclosporin A and tacrolimus treatment. In contrast, treatment with mTOR inhibitors reduced EC proliferative activity by about $40 \%$, independently of the EC origin. No induction of apoptosis (caspase-3/7 activity) or cytotoxicity (MTS test) was observed. Long-term treatment with high concentrations of sirolimus and everolimus did not enhance the expression of CAM. Stimulation with tumor necrosis factor significantly increased the expression of CAM, independently of the drugs used. None of the mTOR inhibitors influenced the tumor necrosis factor-induced expression of CAM,
\end{abstract}

\section{KARGER}

Fax +41613061234

E-Mail karger@karger.ch

www.karger.com (c) 2008 S. Karger AG, Basel

$1018-1172 / 08 / 0454-0333 \$ 24.50 / 0$

Accessible online at:

www.karger.com/jvr whereas adhesion of PBMC increased significantly, as described by other papers. In summary, neither calcineurin inhibitors nor mTOR inhibitors activate human micro- and macrovascular EC. Therefore, the investigated drugs are unlikely to contribute to EC activation during transplant-associated vasculopathy.

Copyright $\odot 2008$ S. Karger AG, Basel

\section{Introduction}

Endothelial cell (EC) dysfunction/activation is a prominent feature in several diseases ranging from atherosclerosis to transplant rejection. These processes lead to rapid and transient upregulation of proinflammatory molecules, such as adhesion molecules. The expression of E-selectin, vascular and intracellular adhesion molecules (VCAM-1, ICAM-1) in capillaries, and the levels of their soluble forms, correlate with the severity of cellular and humoral rejection $[1,2]$, and may eventually influence patient and graft survival [3]. Endothelial activation and

K. Lehle and S. Schreml contributed equally to this work.
Dr. Karla Lehle

Department of Cardiothoracic Surgery, University of Regensburg

Franz-Josef-Strauss-Allee 11, DE-93042 Regensburg (Germany)

Tel. +49941944 9901, Fax +499419449902

E-Mail karla.lehle@klinik.uni-regensburg.de 
allograft survival have been greatly improved by multiple immunosuppressive drugs [4].

The impact of immunosuppression on individual endothelial properties has been investigated in several in vitro models [5-7]. However, most of these studies used human umbilical veins, immortalized or animal-derived EC often without considering the functional heterogeneity of EC derived from different origins $[8,9]$. The objective of our study was to elucidate the direct impact of mTOR inhibitors (mammalian target of rapamycin) and calcineurin inhibitors (CNI) on EC derived from microand macrovascular origins. mTOR inhibitors are important immunosuppressive drugs that exert synergistic immunomodulatory effects when administered together with CNI as they lead to a sequential blockade of IL-2mediated pathways: CNI lead to a decreased production of IL-2 and mTOR inhibitors block IL-2-activated mTOR signal transduction. Furthermore, a combined regimen of CNI and mTOR inhibitor treatment with dose tapering of the CNI seems to be a clinically efficient strategy, although there is still a lack of data focusing on their effects at specific sites of action. Therefore, we focused on these 2 drug classes. A particular ex vivo-in vitro model using patient-derived EC cultures was applied to closely mimic the in vivo situation of atherosclerotic vessels during the early postoperative period after transplantation with incipient immunosuppression.

\section{Methods}

\section{Cell Culture}

Patient-derived saphenous vein EC (HSVEC) and coronary artery EC (HCAEC) were isolated from patients undergoing coronary artery bypass surgery and orthotopic heart transplantation. Adult dermal EC, cardiac microvascular EC (HMVEC) and HCAEC were purchased from Cambrex (Walkersville, Md., USA) and Promocell (Heidelberg, Germany). All experiments were approved by the local ethics committee and conducted in accordance with the Declaration of Helsinki. EC cultures were cultivated in endothelial-specific medium (EGM-kit; Cat. No. C22010, Promocell) supplemented with 30\% pooled human serum (culture medium with serum; CMS) according to Lehle et al. [10]. These culture conditions are essential for optimal growth of patient-derived EC in the indicated experimental time frame. The purity of the preparations was $99 \%$, as monitored by staining with an anti-human CD31-PE antibody (Ancell, Bayport, Minn., USA), and flow-cytometric analysis (FACSCalibur, BD Biosciences, San Jose, Calif., USA). EC from passages 3-5 were seeded with a density of 4,000 cells $/ \mathrm{cm}^{2}$ in 96 -well plates (Costar, Pleasanton, Calif., USA) using $150 \mu \mathrm{l}$ of CMS per well. After 3 days, the medium was renewed and immunosuppressive drugs were added for $48 \mathrm{~h}$ under standard culture conditions. In order to detect tumor necrosis factor (TNF)-induced expression of E-selectin, VCAM-1 and
ICAM-1, EC were stimulated with $10 \mathrm{ng} / \mathrm{ml}$ TNF (Calbiochem, Bad Soden, Germany) for the last $4 \mathrm{~h}$ (E-selectin) and $20 \mathrm{~h}$ (ICAM1, VCAM-1) of drug treatment, respectively. In order to exclude any influence of the proliferative activity of untreated control cells, we seeded EC with a density of 30,000 cells $/ \mathrm{cm}^{2}$ in 96 -well plates for 2 days, and incubated with each drug for $48 \mathrm{~h}$ as described above. The cells in the resulting confluent monolayer were stable over the next 4 days. Trypan blue exclusion yielded a viability of about $85-95 \%$.

\section{Immunosuppressive Drugs}

Cyclosporin A (CsA) and everolimus (Eve) (Novartis Pharma, Nürnberg, Germany), tacrolimus (Tac; Fujisawa Healthcare, Deerfield, Ill., USA), and sirolimus (Sir; Wyeth-Ayerst, Madison, N.J., USA) were dissolved in $100 \%$ ethanol (10 mM stock solution) and diluted with ethanol and CMS (working concentration of the drug $1 \mu \mathrm{M}$; ethanol always being $0.1 \%, 150 \mu \mathrm{l}$ per well). Control cells were incubated with CMS plus $0.1 \%$ ethanol.

\section{Cell Growth Characteristics}

To determine cell numbers and dimensions, EC were treated as described above, detached by collagenase type 2 (Roche Diagnostics, Basel, Switzerland) treatment and cell suspensions were counted using an automated cell analyzer system allowing both the discrimination of viable cells from dead cells/debris and the determination of average cell volumes (CASY1; Schärfe-System, Reutlingen, Germany). Cell counts were recorded after $48 \mathrm{~h}$ of drug exposure and documented in relation to respective untreated controls (100\%) at the corresponding time points.

\section{Cell Viability, Mitochondrial Activity and Apoptosis}

The metabolic status of EC in culture was determined using the tetrazolium-based mitochondrial dehydrogenase assay (MTS; Promega, Madison, Wisc., USA) according to manufacturer's instructions. EC were incubated with or without immunosuppressive drugs for $47 \mathrm{~h}$ in CMS, which was then replaced by medium (without additives) supplemented with 16\% MTS solution and incubated for $1 \mathrm{~h}$ under standard culture conditions. Absorbance was measured at $490 \mathrm{~nm}$ with a 96-well-plate reader (MWG-Biotech, Ebersberg, Germany) and cellular absorbance was calculated by dividing absorbance per well by cell counts per well.

Apoptosis was determined in cultures (drug treated and untreated) via the activation of caspases-3/7 (Promega) following manufacturer's instructions. After exhausting the supernatants, EC were lysed by addition of a lysis buffer (including caspase-3/7 substrate) and frozen overnight at $-20^{\circ} \mathrm{C}$. Caspase activity was expressed as fluorescence per counted cell. Incubation with 10 $\mu \mathrm{M}$ staurosporine (Sigma, St. Louis, Mo., USA) for $4 \mathrm{~h}$ was used as a positive control.

Simultaneously, experimental series were assayed microscopically for cell viability using the trypan blue exclusion technique.

\section{Proliferative Activity}

Proliferative activity was assessed using 2 techniques:

(1) $\left[\right.$ Methyl- $\left.{ }^{3} \mathrm{H}\right]$-thymidine incorporation: [Methyl- $\left.{ }^{3} \mathrm{H}\right]$-thymidine $0.1 \mu \mathrm{Ci}$ (Amersham Pharmacia, Buckinghamshire, UK) was added per well during the last $24 \mathrm{~h}$ of the 48 -hour drug incubation period. Cells were dissociated with $2.5 \%$ trypsin/1\% EDTA (BioWhittaker, Waldersville, Md., USA) and harvested on glass- 
fiber membranes (Filtermat B; Wallac, Turku, Finland) using a semiautomatic cell harvester (Inotech, Nabburg, Germany). Incorporated radioactive [methyl- ${ }^{3} \mathrm{H}$ ]-thymidine was measured in corrected counts per minute (ccpm) per well and documented relative to respective untreated controls.

(2) Flow-cytometric univariant DNA analysis was performed to validate changes in [methyl- $\left.{ }^{3} \mathrm{H}\right]$-thymidine incorporation of mTOR-inhibitor-exposed EC. EC were grown in T75 culture flasks ( 4,000 cells $/ \mathrm{cm}^{2}, 12 \mathrm{ml}$ CMS). At day 4 (80\% confluence), the medium was renewed and supplemented with or without mTOR inhibitors $(10 \mu \mathrm{M})$. After $24 \mathrm{~h}$ of incubation, cells were harvested by collagenase digestion, washed twice in $\mathrm{PBS} / 0.2 \%$ BSA and fixed in $70 \%$ methanol (Merck, Darmstadt, Germany) at $4^{\circ} \mathrm{C}$ overnight $\left(1 \times 10^{6} \mathrm{cells} / \mathrm{ml}\right)$. For propidium-iodide staining, cell suspensions were again washed, pre-incubated with $10 \mathrm{U} / \mathrm{ml}$ RNAse (Sigma) $\left(37^{\circ} \mathrm{C}, 20 \mathrm{~min}\right)$, and propidium iodide was added (50 $\mu \mathrm{g} / \mathrm{ml}, 15-30 \mathrm{~min})$. DNA histograms were recorded using a FACSCalibur flow cy tometer. High-quality cell cycle analysis was performed with the WinCycle software package (Phoenix Flow Systems, San Diego, Calif., USA).

\section{Expression of Cellular Adhesion Molecules}

Drug-treated and untreated EC monolayers in 96-well plates were washed with pre-warmed PBS, fixed with methanol/acetone $\left(1: 1,-20^{\circ} \mathrm{C}, 10 \mathrm{~min}\right)$, and stored at $-20^{\circ} \mathrm{C}$ to determine cellular amounts of VCAM-1, ICAM-1 and E-selectin using a cellular ELISA [10]. In a separate experimental setup, the cell count was analyzed under identical culture conditions using CASY1. The expression of cellular adhesion molecules (CAM) was defined as the ratio of absorbance per culture area $\left(0.3 \mathrm{~cm}^{2}\right)$ and the cell count of the respective sample. The activation factor (AF) defines the proportions of TNF-stimulated expression and basal expression.

For histological analysis, EC were grown on chamber slides (Nunc, Roskilde, Denmark) up to confluence, treated with TNF or culture medium for $4 \mathrm{~h}$, washed with PBS, fixed in acetone/ methanol (1:1) for $10 \mathrm{~min}$ at $-20^{\circ} \mathrm{C}$ and labeled using an FITCconjugated monoclonal anti-human CD62E (E-selectin) antibody (Dianova, Hamburg, Germany).

\section{Adhesion of Peripheral Blood Mononuclear Cells}

Peripheral blood mononuclear cells (PBMC) were separated from EDTA peripheral blood of healthy volunteers by FicollPaque density gradient centrifugation (density: $1.077 \mathrm{~g} / \mathrm{ml}$, Amersham Biosciences, Uppsala, Sweden) and washed in PBS. PBMC $\left(1 \times 10^{7}\right.$ cells $\left./ \mathrm{ml}\right)$ were stained with Calcein-AM $(5 \mu \mathrm{M}$, $15 \mathrm{~min}, 37^{\circ} \mathrm{C}$; Molecular Probes, Eugene, Oreg., USA), washed twice with PBS, centrifuged at $400 \mathrm{~g}$ (10 min, room temperature), and resuspended in PBS $\left(2 \times 10^{7} \mathrm{PBMC} / \mathrm{ml}\right)$. The ratio of the number of stained PBMC and respective fluorescence was calculated to quantify the number of adherent PBMC (standard curve). The adhesion assay was performed as previously described by De Clerck et al. [11]. EC were cultivated in 96-well microtiter plates and incubated with immunosuppressive drugs as described above. For the last $4 \mathrm{~h}$ of incubation with drugs, EC were treated with 10 ng/ml TNF or PBS as a control. Afterwards, EC were washed with pre-warmed CMS and incubated with $1.2 \times 10^{5}$ labeled PBMC per well at $37^{\circ} \mathrm{C}$ for $30 \mathrm{~min}$. Nonadherent PBMC in the supernatant were removed by washing 3 times. The fluorescence of the adherent PBMC was measured (excitation $485 \mathrm{~nm}$, emission 535 $\mathrm{nm}$ ). In a separate set of experiments, the number of EC were measured with CASY1 and the ratio of adherent PBMC (via standard curve) to EC was determined.

\section{Statistics}

Data are given as mean (quadruplicate samples for each culture) $\pm \mathrm{SD}$. Wilcoxon signed rank test was used to verify differences between drug-treated and untreated control cells. Most parameters were documented in relation to respective untreated controls. The effect of different drugs on EC was analyzed using the Mann-Whitney rank sum test. Statistical significance was considered to be $\mathrm{p}<0.05 . \mathrm{p}<0.01$ was considered to be highly significant; results are marked with 1 or 2 asterisks within the graphs, respectively.

\section{Results}

\section{Impact of Immunosuppressive Drugs on EC Viability} and Proliferation

High concentrations of Tac $(1 \mu \mathrm{M})$ did not affect viability (trypan blue staining, MTS test) and absolute cell count in the monolayers of micro- and macrovascular EC. However, the incorporation of [methyl- $\left.{ }^{3} \mathrm{H}\right]$-thymidine was reduced for HCAEC. Reduction of the drug concentration in the culture medium $(0.1-100 \mathrm{nM})$ did not influence the amount of EC in the monolayer compared to untreated control cells (data not shown). At the same concentration CsA did not influence cell growth of HSVEC and HMVEC. However, HCAEC showed a higher sensitivity to this CNI. Compared to untreated control cells, incubation with $1 \mu \mathrm{M}$ CsA reduced cell counts significantly by about $20-30 \%$ (fig. 1). The effect was verified by measuring the incorporation of [methyl- $\left.{ }^{3} \mathrm{H}\right]$-thymidine (not significant, fig. 1). The mitochondrial activity per remaining cell (MTS reaction) was not influenced by drug treatment (data not shown). The effect of CsA on the cell growth of HCAEC was dose dependent. Thus, incubation of HCAEC with low and therapeutic concentrations of CsA (0.1-100 $\mathrm{nM}$ ) did not affect the cell count in the monolayer (data not shown). In addition, in a preliminary experiment we showed that the time to reach the maximum drug effect was more than $36 \mathrm{~h}\left(\mathrm{t}^{1} / 2\right.$ being $29-30 \mathrm{~h}, \mathrm{t}^{1 / 2} / 2$ reflecting the time at which half maximal inhibition of cell growth was attained). Therefore, we fixed an experimental time of $48 \mathrm{~h}$, as mentioned above. High concentrations $(1 \mu \mathrm{M})$ of Sir and Eve delayed cell growth. After $48 \mathrm{~h}$ of treatment the cell density was about $40 \%$ lower than untreated controls (HSVEC: $\mathrm{p}<0.01$; HCAEC and HMVEC: $\mathrm{p}<0.05$; fig. 1a). Furthermore, drug exposure did not systematically modify EC volume (e.g. HSVEC: untreated controls: $4,360 \pm 545 \mathrm{fl} ; \mathrm{CsA}: 4,520 \pm 765 \mathrm{fl}$; Tac: 4,250 $\pm 695 \mathrm{fl}$; 

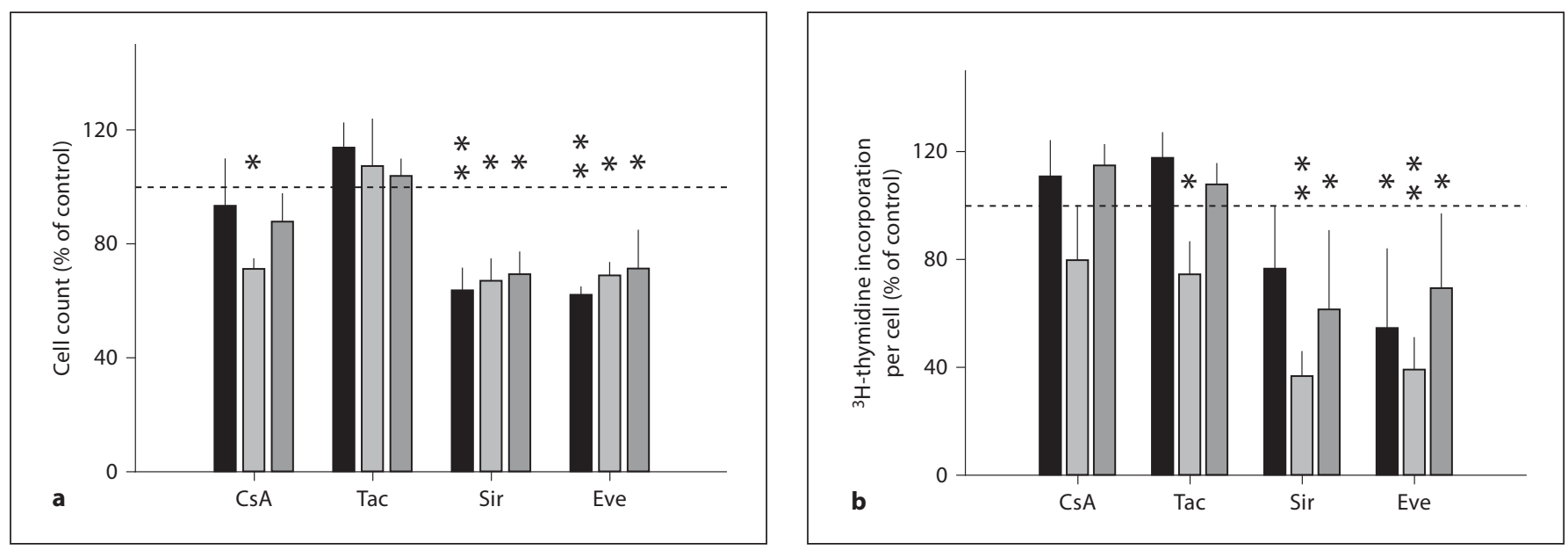

Fig. 1. Viability and growth of macro- and microvascular EC after incubation with CNI or mTOR inhibitors. Cell count (a) and incorporation of [methyl- $\left.{ }^{3} \mathrm{H}\right]$-thymidine per cell (b) were documented after 48 h. HSVEC (black bars, $\mathrm{n}=10$ ), HCAEC (light grey bars, $\mathrm{n}=6$ ) and HMVEC (dark grey bars, $\mathrm{n}=4$ ) were treated with Sir and Eve $(1 \mu \mathrm{M})$. Values are a percentage of the difference between mean treatment and control values (dashed line $=100 \%) .{ }^{*} \mathrm{p}<0.05 ;{ }^{*} \mathrm{p}<0.01$.

Sir: $3,895 \pm 570 \mathrm{fl}$; Eve: $3,980 \pm 580 \mathrm{fl})$. Reduced cell growth in cultures treated with mTOR inhibitors was accompanied by a significantly reduced overall [methyl- $\left.{ }^{3} \mathrm{H}\right]$-thymidine uptake as opposed to the controls, which indicates mTOR inhibitor-induced cytostasis (HSVEC: $\mathrm{p}<0.05$ for Eve; HCAEC: $\mathrm{p}<0.01$ for Eve and Sir; HMVEC: $\mathrm{p}<0.05$ for Eve and Sir; fig. 1b). Using therapeutic concentrations (CsA: 0.1 $\mu$ M; Tac, Sir and Eve: 0.01 $\mu \mathrm{M})$, the impact on EC viability and proliferation described above was confirmed.

\section{Impact of mTOR Inhibitors on Cell Cycle and \\ Potential Apoptosis Induction}

The inhibition of cell growth by mTOR inhibitors was obviously not due to an induction of programmed cell death, as verified via a caspase-3/7 activity assay (fig. $2 a$ ), but clearly resulted from the critical reduction in proliferative activity, of about a 50\% decrease in S-phase fraction, determined by flow-cytometric DNA histogram analysis (fig. 2b).

\section{Impact of Immunosuppressive Drugs on the Expression of CAM}

To elucidate the effect of immunosuppressive drugs on the expression of CAM by EC grown to confluence, monolayers of EC were exposed to high concentrations $(1 \mu \mathrm{M})$ of CsA, Tac, Sir, and Eve for $48 \mathrm{~h}$. With respect to the anti-inflammatory activity of mTOR inhibitors (see above), the expression of CAM per cell was calculated. As shown in figure $3 \mathrm{a}-\mathrm{c}$, none of the CNI or mTOR inhibitors affected the basal cellular expression of CAM of any of the studied cell types. Stimulation with TNF resulted in a significant increase in the expression of each CAM $(\mathrm{p}<0.01)$. The increased expression of E-selectin for example, was shown in a representative fluorescence staining in figure $4 \mathrm{a}$. The activation of the cells with TNF was verified in figures $3 \mathrm{~d}-\mathrm{f}$ as the ratio of the absorbance after TNF stimulation and the basal absorbance. This activation factor (AF) was independent of the pretreatment with CNI and mTOR-inhibitors. However, under control conditions the AF of ICAM-1 and E-selectin were significantly higher for HMVEC than for EC of other origins (fig. 3d-f).

\section{Impact of Immunosuppressive Drugs on the}

Adhesion of Leukocytes

The upregulation of CAM could be verified by the adhesion of PBMC to the surface of drug-treated EC. Stimulation of EC with TNF resulted in an significant increase in the adhesion of freshly prepared PBMC as shown for HSVEC in figure $4 \mathrm{~b}$. While CsA and Tac did not affect the adhesion of PBMC to EC, incubation of EC with high concentrations of both mTOR inhibitors $(1 \mu \mathrm{M})$ resulted in a significant increase in TNF-induced PBMC adhesion (fig. 4b). The other cell types provided analogous data (data not shown). 


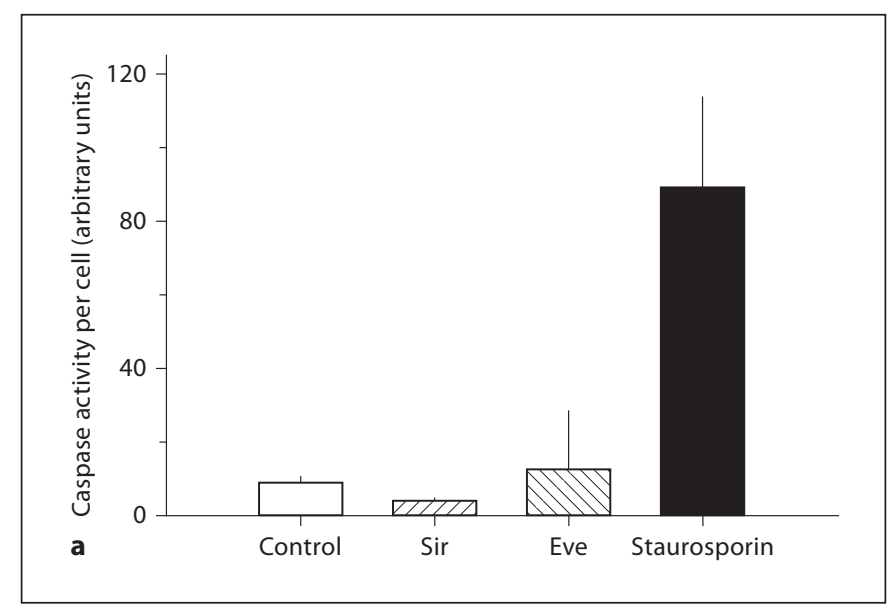

Fig. 2. Impact of Sir and Eve $(1 \mu \mathrm{M})$ on cell growth, apoptosis and proliferative activity of HSVEC in monolayer culture. HSVEC were treated with mTOR inhibitors. The caspase- $3 / 7$ activity per cell (a) and the flow-cytometric univariant DNA analysis (b) describe the proliferative activity of the cells. The proportion of cells in the cell cycle phases were recorded as a percentage. $10 \mu \mathrm{M}$ staurosporin was used as a positive control. SPF $=\mathrm{S}$-phase fraction. ${ }^{* *} \mathrm{p}<0.01$.

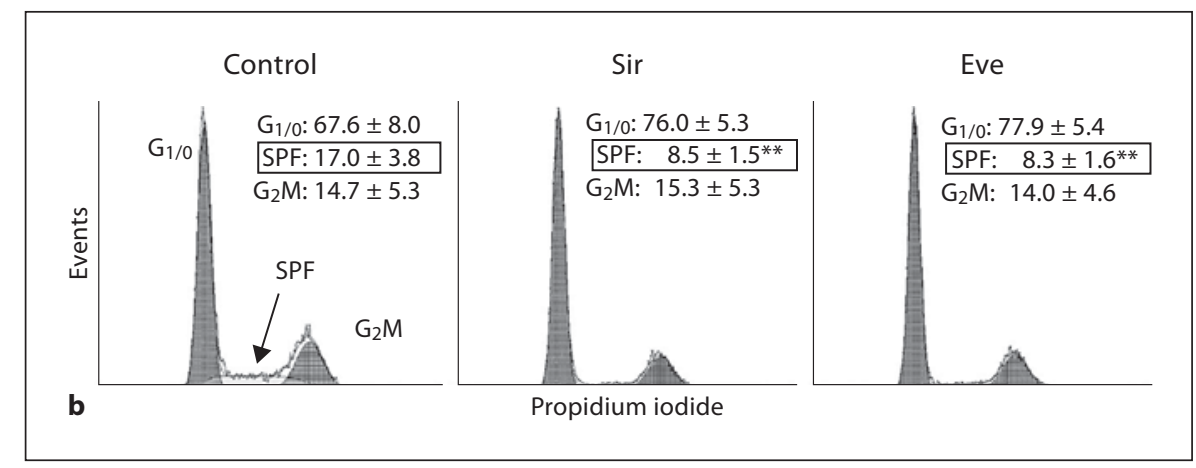

\section{Impact of Immunosuppressive Drugs on CAM Expression of EC Seeded in a Hyperconfluent Monolayer}

To exclude any influence of the proliferative activity of untreated control cells, another set of experiments was repeated with a hyperconfluent monolayer known to auto-inhibit cell proliferation and as a result leave cell counts virtually unchanged. As shown in figure $5 \mathrm{a}$, longterm drug treatment $(48 \mathrm{~h})$ of nonproliferating HSVEC did not start an induction of E-selectin (control: 66,000 $\pm 27,825 \mathrm{cells} / \mathrm{cm}^{2}$; CsA: $77,000 \pm 29,300 \mathrm{cells} / \mathrm{cm}^{2}$; Tac: $70,400 \pm 28,800 \mathrm{cells} / \mathrm{cm}^{2}$; Sir: $60,450 \pm 24,300$ cells/ $\mathrm{cm}^{2}$; Eve: $57,200 \pm 23,900$ cells $/ \mathrm{cm}^{2}$; not significant). TNF was used as a positive control for the stimulation of untreated control cells. In addition, preincubation of HSVEC with drugs ( $44 \mathrm{~h}$ ) did not affect the TNF-induced expression of adhesion molecules. The AF was independent of drug disposure (fig. 5b). The other cell types provided analogous data. According to the expression of Eselectin, drug treatment showed no influence on the basal-induced and TNF-induced expressions of ICAM- 1 and VCAM-1 (data not shown). However, drug treatment of EC affected the TNF-induced adhesion of PBMC in a dif- ferent way. While CNI did not affect the PBMC adhesion on HSVEC (CsA: $90 \pm 60 \%$, Tac: $133 \pm 68 \%$ of untreated control value), preincubation of EC with MTOR inhibitors $(1 \mu \mathrm{M})$ resulted in an increase in the amount of adherent PBMC on EC (Sir: $134 \pm 70 \%$, Eve: $171 \pm 77 \%$ of untreated control value). Due to the high interindividual variability of each cell culture, the differences were not significant. This could be detected for the other cell types (data not shown).

\section{Discussion}

This study directly compares different immunosuppressive drugs under identical culture conditions regarding their potential to modulate micro- and macrovascular endothelial cell properties. The essential new findings are that: (1) Sir and Eve inhibited proliferation of both macro- and microvascular EC, whereas CsA only reduced cell growth of coronary artery EC, and Tac showed generally no antiproliferative activity but exclusively reduced [methyl $\left.{ }^{3} \mathrm{H}\right]$-thymidine incorporation of HCAEC; (2) none of the immunosuppressive drugs induced ex- 

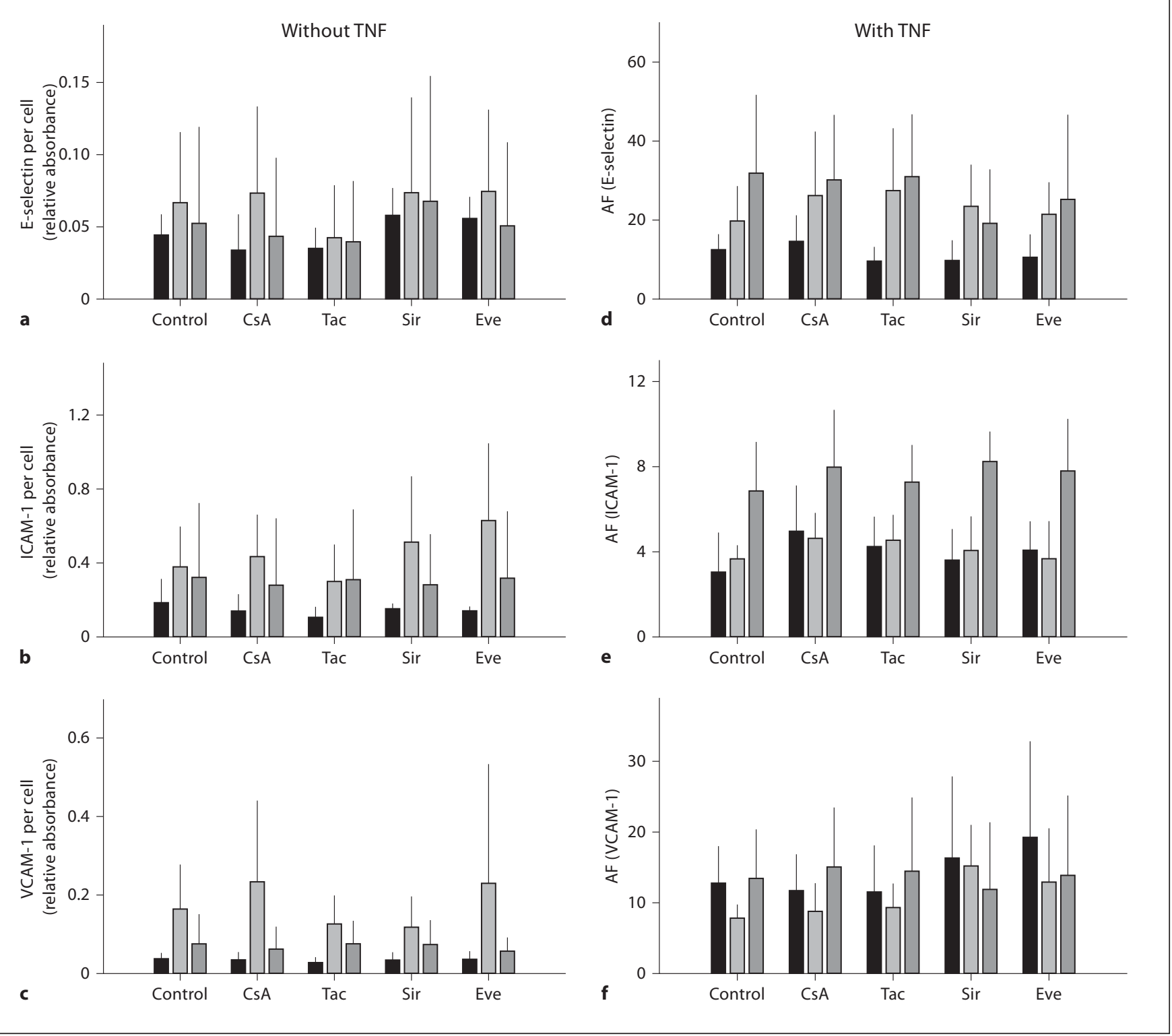

Fig. 3. Expression of CAM on macro- and microvascular EC after pre-incubation with different immunosuppressive drugs. HSVEC (black bars, $\mathrm{n}=10$ ), HCAEC (light grey bars, $\mathrm{n}=6$ ) and HMVEC (dark grey bars, $\mathrm{n}=4$ ) were treated with CsA, Tac, Sir, Eve $(1 \mu \mathrm{M})$ and the medium (control) for $48 \mathrm{~h}$. The basal expression of CAM per cell $(\mathbf{a}-\mathbf{c})$ and the AF $(\mathbf{d}-\mathbf{f})$ of E-selectin $(\mathbf{a}, \mathbf{d})$,
ICAM-1 (b, e) and VCAM-1 (c, f) were documented as mean \pm SD. The TNF-induced expression of CAM was analyzed as the absorption of CAM after drug treatment and TNF incubation, and $\mathrm{AF}$ was defined as the proportion of TNF-stimulated versus basal absorbance. pression of the investigated adhesion molecules; (3) mTOR inhibitors increased the TNF-induced adhesion of PBMC.

In our experiments, high concentrations of CsA and Tac exclusively exerted antiproliferative effects on HCAEC in contrast to EC from other vessels. The effect disappeared at lower and therapeutic concentrations (0.1-10 nM) of both drugs. Dose- and time-dependent responses to CNI treatment have already been described for diverse nonendothelial and endothelial cell types [12-14]. While the cell growt th of human late-outgrowth endothelial progenitor cells and mature aortic EC was not affect- 


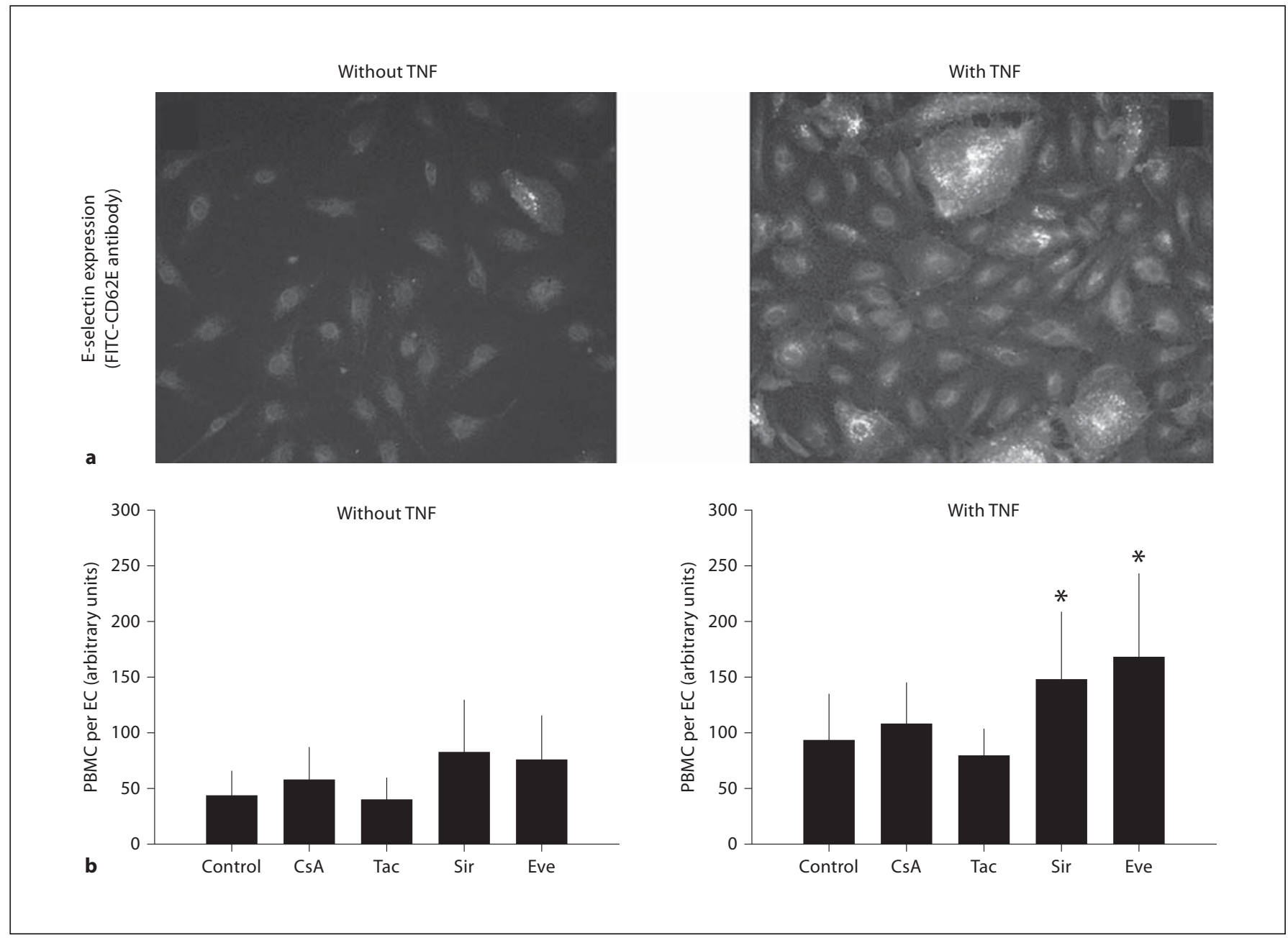

Fig. 4. Expression of E-selectin and PBMC adhesion of drug-treated and untreated HSVEC. a Immunofluorescent staining of a representative HSVEC culture using a FITC-conjugated anti-CD62E antibody. Basal expression (left picture) and TNF-induced expression after $4 \mathrm{~h}$ (right picture) of control cells. b HSVEC $(\mathrm{n}=5)$ were pretreated with CsA, Tac, Sir, Eve $(1 \mu \mathrm{M})$ and the medium

(control) for $44 \mathrm{~h}$ and then incubated with PBS (left picture) and TNF (right picture) for $4 \mathrm{~h}$. Freshly prepared PBMC were incubated with drug-treated and untreated EC, and the amount of adherent PBMC per cell was determined. ${ }^{*} \mathrm{p}<0.05$, comparing drug-treated versus untreated EC.

ed by high concentrations of both CNI [13, 14], CsA reduced viability of EC from the blood-brain barrier [15] and medullary thick ascending limb cells [16]. In contrast, Tac did not affect the cell proliferation of these cell types $[12,13,15,16]$. On cellular levels, previous studies reported both enhanced proliferation at low concentrations [6] and decreased cell growth at high concentrations $[12-14,17,18]$. The usage of different EC types (venous, aortic, corneal, microvascular, endothelial progenitor cells or immortalized cell lines) and different incubation times made a comparison of these data difficult. In our present study, all EC types were treated with the

same concentration of CsA under identical culture conditions. Therefore, it is conceivable that the different responses to CsA depended on the higher sensitivity of HCAEC for CsA. However, therapeutic concentrations of CsA (100-300 nM) and of Tac (6-24 nM) did not affect the cell density of drug-treated EC monolayers.

For functional analysis, we demonstrated that none of the CNI exhibited an anti-inflammatory effect in our culture system - not even at peak concentrations. CsA and Tac neither affected the release of IL-6 (data not shown) nor the expression of CAM and the adhesion of PBMC. In contrast to other scientific groups, our experi-

J Vasc Res 2008:45:333-342 

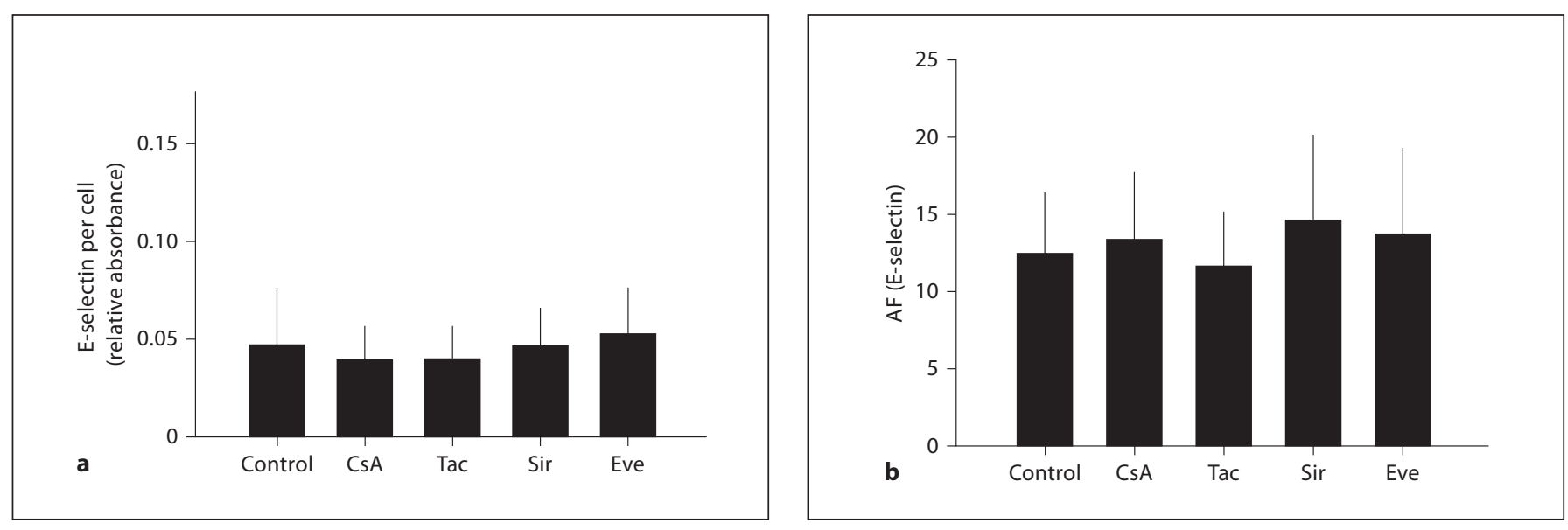

Fig. 5. Basal and TNF-induced expression of cellular E-selectin on HSVEC after pre-incubation with different immunosuppressive drugs. Confluent cultures of HSVEC $(n=6)$ were treated with CsA, Tac, Sir, Eve $(1 \mu M)$ and the medium (control) for $48 \mathrm{~h}$. The basal expression of E-selectin per cell (a) and the AF (b) were recorded as means \pm SD. AF was defined as the proportion of TNF-stimulated ( $4 \mathrm{~h}$ ) versus basal absorbance. a Incubation of the control cells with TNF was used as a positive control.

mental setup should mimic steady-state conditions with an acute episode of TNF stimulation, as possibly seen under in vivo conditions after organ transplantation. Other scientific groups described different effects of CsA. Charreau et al. [5] and Markovic et al. [19] showed, for example, that CsA downregulated the expression of E-selectin and VCAM-1 under concomitant stimulation with TNF, while the expression of ICAM-1 remained unchanged $[19,20]$. Furthermore, Rafiee et al. [21] demonstrated that CsA enhanced leukocyte binding by human intestinal microvascular EC (HIMEC) through inhibition of p38 MAPK and iNOS. They used HIMEC to provide a mechanistic explanation regarding a proinflammatory effect of CsA on the organ-specific microvascular endothelium, and to demonstrate the failure of this compound in the long-term treatment of chronic inflammatory bowel disease. We speculate that the different proinflammatory responses could be reduced to the organ-specific heterogeneity of EC [8] or different culture conditions. Karlsson and Nassberger [22] confirmed our finding that Tac does not affect EC activation in response to inflammatory stimuli like TNF. Moreover, up to supratherapeutic Tac levels, there seem to be no deleterious effects on capillaries in vitro [7].

In contrast, mTOR inhibitors inhibit such proliferation of both hematopoietic and nonhematopoietic cells, showing their action as potent immunosuppressive drugs $[23,24]$. Inhibition of smooth muscle cell proliferation is especially relevant for protection against cardiac allograft vasculopathy (CAV) [25]. Moreover, one has to keep in mind the participation of endothelial activation/dysfunction in the process of CAV [26]. To demonstrate the impact of mTOR inhibitors on the activation status of the endothelial layer after transplantation or stent implantation, we documented a significant decrease in EC growth within the therapeutic range of immunosuppressive efficacy of Sir and Eve. Previous studies agreed with our data and speculated that the mechanism of cell death appeared to be apoptosis induced by caspase- 3 activation [27-29]. However, our data, as well as those of Miriuka et al. [13], clearly showed no caspase-3 activation under mTOR inhibition. Instead, we observed cell-cycle arrest without a cytotoxic effect. We speculate that the therapeutic approach of mTOR inhibitors to reduce intimal hyperplasia by inhibition of smooth muscle cell proliferation is paralleled by a reduced ability to maintain vascular reendothelialization. Thus, inhibition of EC proliferation by mTOR inhibitors indicates that Sir and Eve delay reendothelialization after balloon dilatation and combined introduction of drug-eluting stents, as seen in humans, 3 weeks after stent deployment $[13,30,31]$.

The central event in the development of CAV is the inflammatory response to immune- or non-immune-mediated endothelial damage, which is also characterized by the upregulation of adhesion molecules and the subsequent binding of leukocytes [25]. Despite the absence of acute inflammatory processes in heart transplant patients, the concentration of circulating adhesion mole- 
cules has been reported to be enhanced [32]. With our culture system, we are able to mimic such steady-state conditions to evaluate the specific effects of immunosuppressive drugs on EC stimulation and to study the effect of acute inflammatory events on the activation status of EC. We could show that long-term incubation of microand macrovascular EC with both mTOR inhibitors had no effect on the basal release of IL-8 and MCP-1 [27], as well as on the expression of CAM. Due to different experimental protocols in the literature [5-7, 13, 14], using hyperconfluent seeding of $\mathrm{EC}$ for $24 \mathrm{~h}$ accompanied by drug treatment for an additional $24-48 \mathrm{~h}$, we validated our previous data in a confluent monolayer experiment. The drug effects were independent of the seeding protocol. Furthermore, we recently reported on an inhibition of basal IL-6 synthesis of HCAEC by both mTOR inhibitors [24], which could not be detected for HSVEC and HUVEC. We concluded that Sir and Eve per se do not result in activation of the endothelium. Specific anti-inflammatory and anticytokine effects of Sir were also documented in recent in vitro $[24,27]$ and in vivo [33] studies. In addition to that, the potential benefit of mTOR inhibitors, in combination with reduced doses of calcineurin inhibitors, was verified in clinical studies $[34,35]$.

TNF stimulation of our micro- and macrovascular EC enhanced expression of CAM and the adhesion of leukocytes. The increased density of E-selectin and VCAM-1 on microvascular EC was also documented by Stins et al. [36]. We postulate a cell type-specific heterogeneity of our EC [8]. In our study, none of the mTOR inhibitors influenced the TNF-induced expression of CAM. Paradoxically, the adhesion of PBMC increased significantly. Previous reports strengthen our data and showed that the TNF-induced expression of VCAM-1 was not affected by Eve [37]. In contrast, Sir downregulated complement-induced ICAM-1 expression in a concentration-dependent manner on immortalized porcine aortic EC [38]. This may be due to different stimulation mechanisms comparing TNF and complement, and the fact that our cells were not serum starved. In our cell culture system, serum starvation resulted in significant cell loss, whereas a high content of serum was essential for optimal growth of our patient-derived cells. It cannot be excluded, for example, that CNI might induce CAM after a period of serum starvation. However, this could not be detected in our culture system. The unchanged endothelial expression of CAM and the paradoxically increased TNF-induced leukocyte binding after treatment with mTOR inhibitors might be a result of poor sensitivity of the used assays (leukocyte binding assay, cellular ELISA). However, we could validate our cellular ELISA data with flow-cytometric analysis (data not shown). A similar situation was described by Rafiee et al. [21]. CsA enhances leukocyte binding by HIMEC leaving CAM expression of these microvascular EC unaffected. Obviously, other factors like elevated $\mathrm{Lp}$ (a) levels can lead to monocyte recruitment via Mac-1 integrin interaction [39], an effect which is widely independent of CAM activation. Additional experiments are necessary to study the complex network of endothelial dysfunction after drug treatment.

In summary, treatment of EC with mTOR inhibitors delayed reendothelialization in a dose-dependent manner [24]. However, our data also show that neither calcineurin inhibitors nor mTOR-inhibitors activated EC per se. This suggests that the chronic inflammatory process after transplantation [32] is not triggered by the specific effects of immunosuppressive drugs on the EC monolayer. Anti-inflammatory effects of mTOR-inhibitors may also be beneficial in future clinical trials by allowing a withdrawal or dose-reduction of CNI in the immunosuppressive regimen after cardiac transplantation.

\section{Acknowledgments}

The authors gratefully acknowledge the excellent technical assistance of A. Urbanek, S. Bergman, C. Leykauf, K. Bielenberg, K. Hollnberger and M. Wondrak. The project was supported by Novartis-Pharma GmbH (Nürnberg, Germany).

\section{References}

1 Weis M, von Scheidt W: Cardiac allograft vasculopathy: a review. Circulation 1997;96: 2069-2077.

2 Wu YW, Lee CM, Lee YT, Wang SS, Huang PJ: Value of circulating adhesion molecules in assessing cardiac allograft vasculopathy. J Heart Lung Transplant 2003;22:1284-1287.

3 Olyaei AJ, de Mattos AM, Bennett WM: Nephrotoxicity of immunosuppressive

mTOR and Calcineurin Inhibitors and

Endothelial CAM Expression drugs: new insight and preventive strategies. Curr Opin Crit Care 2001;7:384-389.

4 Weis M, Wildhirt SM, Schulze C, Pehlivanli S, Rieder G, Wolf WP, Wilbert-Lampen U, Meiser BM, Enders G, von Scheidt W: Coronary vasomotor dysfunction in the cariac allograft: impact of different immunosuppressive regimens. J Cardiovasc Pharmacol 2000; 36:776-784.
5 Charreau B, Coupel S, Goret F, Pourcel C, Soulillou JP: Association of glucocorticoids and cyclosporin A or rapamycin prevents Eselectin and IL- 8 expression during LPSand TNF-mediated endothelial cell activation. Transplantation 2000;69:945-953.

6 Trapp A, Weis M: The impact of immunosuppression on endothelial function. J Cardiovasc Pharmacol 2005;45:81-87. 
7 Wilasrusmee C, Da Silva M, Singh B, Siddiqui J, Bruch D, Kittur S, Wilasrusmee S, Kittur DS: Morphological and biochemical effects of immunosuppressive drugs in a capillary tube assay for endothelial dysfunction. Clin Transplant 2003;17:6-12.

8 Aird WC: Spatial and temporal dynamics of the endothelium. J Thromb Haemost 2005;3: 1392-1406.

9 Ribatti D, Nico B, Vacca A, Roncali L, Dammacco F: Endothelial cell heterogeneity and organ specificity. J Heamatother Stem Cell Res 2002;11:81-90.

10 Lehle K, Buttstaedt J, Birnbaum DE: Expression of adhesion molecules and cytokines in vitro by endothelial cells seeded on various polymer surfaces coated with titaniumcarboxonitride. J Biomed Mater Res 2003;65: 393-401.

11 De Clerck LS, Bridts CH, Mertens AM, Moens MM, Stevens WJ: Use of fluorescent dyes in the determination of adherence of human leucocytes to endothelial cells and the effect of fluorochromes on cellular function. J Immunol Methods 1994;172:115124.

12 Esposito C, Fornoni A, Cornacchia F, Bellotti N, Fasoli G, Foschi A, Mazzucchelli I, Mazzullo T, Semeraro L, Dal Canton A: Cyclosporine induces different responses in human epithelial, endothelial and fibroblast cell cultures. Kidney Int 2000;58:123-130.

13 Miriuka SG, Rao V, Peterson M, Tumiati L, Delgado DH, Mohan R, Ramzy D, Stewart D, Ross HJ, Waddell TK: mTOR inhibition induces endothelial progenitor cell death. Am J Transplant 2006;6:2069-2079.

14 Mohacsi PJ, Tuller D, Hulliger B, Wijngaard PL: Different inhibitory effects of immunosuppressive drugs on human and rat aortic smooth muscle and endothelial cell proliferation stimulated by platelet-derived growth factor or endothelial cell growth factor. J Heart Lung Transplant 1997;16:484492.

15 Kochi S, Takanaga H, Matsuo H, Naito M, Tsuruo T, Sawada Y: Effect of cyclosporin A or tacrolimus on the function of blood-brain barrier cells. Eur J Pharmacol 1999;372:287295.

16 Wu MS, Yu HM, Hong JJ, Lai BC, Huang CC, Vandewalle A: Cyclosporine, but not FK 506 and rapamycin, enhances cell proliferation in mouse medullary thick ascending cultured cells. Transplant Proc 1998;30:35653566.

17 Garweg JG, Wegmann-Burns M, Goldblum D: Effects of daunorubicin, mitomycin C, azathioprine and cyclosporin $\mathrm{A}$ on human retinal pigmented epithelial, corneal endothelial and conjunctival cell lines. Graefes Arch Clin Exp Ophthalmol 2006;244:382389.
18 Seki Y, Toba K, Fuse I, Sato N, Niwano H, Takahashi $\mathrm{H}$, Tanabe N, Aizawa Y: In vitro effect of cyclosporin A, mitomycin $\mathrm{C}$ and prednisolone on cell kinetics in cultured human umbilical vein endothelial cells. Thromb Res 2005;115:219-228.

19 Markovic S, Raab M, Daxecker H, Griesmacher A, Karimi A, Müller MM: In vitro effects of cyclosporin A on the expression of adhesion molecules on human umbilical vein endothelial cells. Clin Chim Acta 2002; 316:25-31.

20 Maksymowicz M, Lukomska B, Ziolkowska A, Janczewska S, Cybulska E, Olszewski WL: Cyclosporin A decreases lymphocyte migration to the heart allograft through suppression of their L-selectin expression. Ann Transplant 1998;3:34-36.

21 Rafiee P, Johnson CP, Li MS, Ogawa H, Heidemann J, Fisher PJ, Lamirand TH, Otterson MF, Wilson KT, Binion DG: Cyclosporine A enhances leukocyte binding by human intestinal microvascular endothelial cells through inhibition of p38 MAPK and iNOS: paradoxical proinflammatory effect on the microvascular endothelium. J Biol Chem 2002;277:35605-35615.

22 Karlsson H, Nassberger L: FK506 suppresses the mitogen-induced increase in lymphocyte adhesiveness to endothelial cells, but does not affect endothelial cell activation in response to inflammatory stimuli. Transplantation 1997;64:1217-1220.

23 Mancini D, Pinney S, Burkhoff D, LaManca J, Itescu S, Burke E, Edwards N, Oz M, Marks AR: Use of rapamycin slows progression of cardiac transplantation vasculopathy. Circulation 2003;108:48-53.

24 Schreml S, Lehle K, Birnbaum DE, Preuner JG: mTOR-inhibitors simultaneously inhibit proliferation and basal IL- 6 synthesis of human coronary artery endothelial cells. Int Immunopharmacol 2007;7:781-791.

25 Pinney SP, Mancini D: Cardiac allograft vasculopathy: advances in understanding its pathophysiology, prevention, and treatment. Curr Opin Cardiol 2004;19:170-176.

26 Valantine HA: Cardiac allograft vasculopathy: central role of endothelial injury leading to transplant 'atheroma'. Transplantation 2003;76:891-899.

27 Lehle K, Birnbaum DE, Preuner JG: Predominant inhibition of interleukin- 6 synthesis in patient-specific endothelial cells by mTOR inhibitors below a concentration range where cell proliferation is affected and mitotic arrest takes place. Transplant Proc 2005;37: 159-161.
28 Riesterer O, Zingg D, Hummerjohann J, Bodis S, Pruschy M: Degradation of PKB/ Akt protein by inhibition of the VEGF receptor/mTOR pathway in endothelial cells. Oncogene 2004;23:4624-4635.

29 Sugatani T, Hruska KA: Akt1/Akt2 and mammalian target of rapamycin/Bim play critical roles in osteoclast differentiation and survival, respectively, whereas Akt is dispensable for cell survival in isolated osteoclast precursors. J Biol Chem 2005;280: 3583-3589.

30 Farb A, Sangiorgi G, Carter AJ, Walley VM, Edwards WD, Schwartz RS, Virmani R: Pathology of acute and chronic coronary stenting in humans. Circulation 1999;99:44-52.

31 Grewe PH, Deneke T, Machraoui A, Barmeyer J, Muller KM: Acute and chronic tissue response to coronary stent implantation: pathologic findings in human specimen. J Am Coll Cardiol 2000;35:157-163.

32 Wildhirt SM, Schulze C, Conrad N, Bauernschmitt R, Lange R, von Scheidt W: Persistently increased systemic, but not cardiacspecific, adhesion molecule expression and coronary endothelial dysfunction in human cardiac allografts. J Thorac Cardiovasc Surg 2005; 130:1175.

33 Schmid C, Heemann U, Azuma H, Tilney NL: Rapamycin inhibits transplant vasculopathy in long-surviving rat heart allografts. Transplantation 1995;60:729-733.

34 Bestard O, Cruzado JM, Grinyo JM: Calcineurin-inhibitor-sparing immunosuppressive protocols. Transplant Proc 2005;37: 3729-3732.

35 Merville P: Combating chronic renal allograft dysfunction: optimal immunosuppressive regimens. Drugs 2005;65:615-631.

36 Stins MF, Gilles F, Kim KS: Selective expression of adhesion molecules on human brain microvascular endothelial cells. J Neuroimmunol 1997;76:81-90.

37 Haubitz M, Brunkhorst M: Influence of a novel rapamycin analogon SDZ RAD on endothelial tissue factor and adhesion molecule expression. Transplant Proc 2002;34: 1124-1126.

38 Wood SC, Bushar G, Tesfamariam B: Inhibition of mammalian target of rapamycin modulates expression of adhesion molecules in endothelial cells. Toxicol Lett 2006;165: 242-249.

39 Sotiriou SN, Orlova VV, Al-Fakhri N, Ihanus E, Economopoulou M, Isermann B, Bdeir K, Nawroth PP, Preissner KT, Gahmberg CG, Koschinsky ML, Chavakis T: Lipoprotein(a) in atherosclerotic plaques recruits inflammatory cells through interaction with Mac-1 integrin. FASEB J 2006;20:559-561. 